\title{
Middle ear osteoma: case report and review of literature
}

\section{Abstract}

Osteomas are benign lesions that arise in the temporal bone commonly in the external canal. However middle ear osteomas are extremely rare. They are usually asymptomatic and discovered incidentally or may present with conductive hearing loss. This article reports a case of middle ear promontory osteoma with review of literature.
Volume 10 Issue 6 - 2018

Ossama Hamid, Amr Ossama Abdelhamid, Togan Taha

Ain Shams University, Egypt

Correspondence: Ossama Hamid, Ain Shams University, Mohamed Badr Rakha Street, 7th district, Obour City, Tel 00201222145199,Email osamahamid@gmail.com

Received: August 12, 2018 | Published: November 16, 2018

\section{Introduction}

Temporal bone osteomas are benign tumors of lamellar bone and are the most widespread neoplasms of the temporal bone. They most commonly arise from the external auditory canal; however its presence in other areas has been reported such as the mastoid region, the squama, the internal auditory canal and the middle ear.

\section{Case report}

A seven year old presented to our clinic with progressive hearing loss with no other ontological symptoms. He had no past history of ear infections and no significant past medical or surgical history. On examination he had bilateral intact tympanic membranes.

Audiological evaluation revealed right normal hearing and left moderate to severe conductive hearing loss.

Computed tomography revealed a lobulated hyper dense lesion arising from the superior wall of the middle ear cavity and pedunculated along the medial wall with $\mathrm{CT}$ features of Osteoma.

The patient's guardians were consulted about the benefits and risks of surgery and declined the surgical option. Patient is currently on follow up plan every one year (Figure 1), (Figure 2) \& (Figure 3).

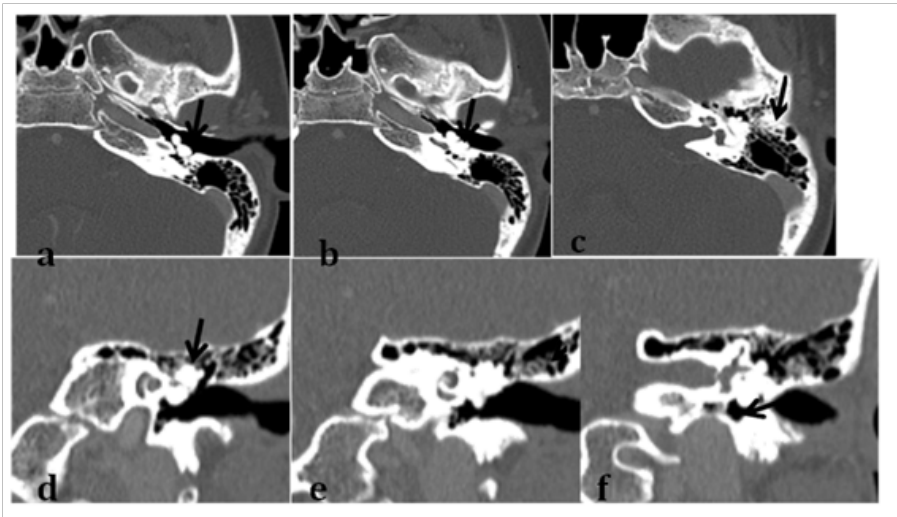

Figure I CT temporal bone, Axial images going from caudal to cranial $(a, b, c)$ and coronal images ) from anterior to posterior (d,e,f ) displaying lobulated hyper dense lesion arising from the superior wall of the middle ear cavity and pedunculated along the medial wall ( black arrows)giving CT features of osteoma.

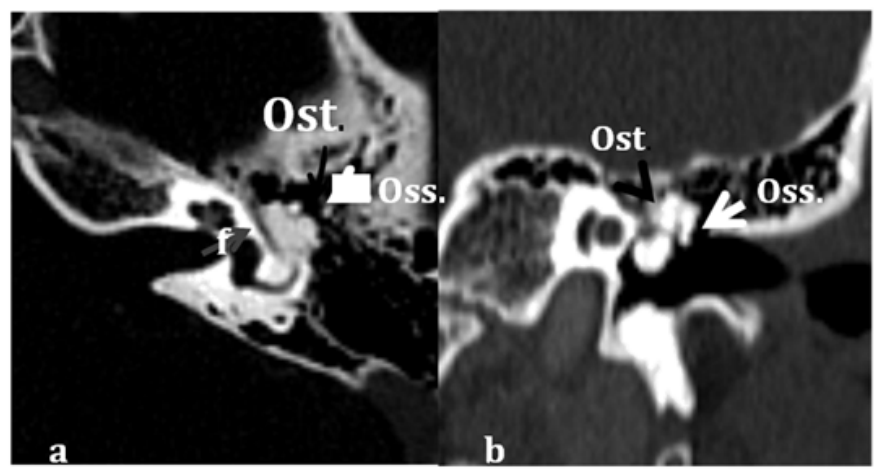

Figure 2 Axial (a) and coronal (b) views displaying Osteoma emanating from superior and medial wall of middle ear cavity, inseparable from Tympanic course of the facial nerve canal (grey arrow). The malleus head, incus body and short process (white arrow) are displaced laterally.

Abbreviations: F, facial nerve canal; OST, osteoma ; OSS, ossicles.

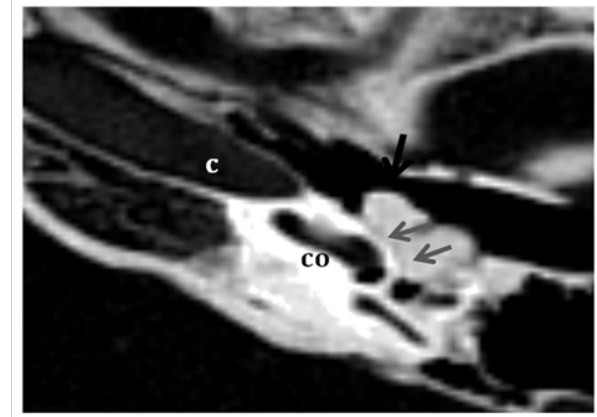

Figure 3 Axial image displaying middle ear Osteoma (black arrow) is well separated from carotid canal (c) and intimately related to but still separated from cochlear promontory (grey arrows).

Abbreviations: $\mathrm{CO}$, basal turn of cochlea.

\section{Discussion}

Osteomas of the temporal bone are usually found in the external auditory canal. However, they may also arise in sites outside the external auditory canal such as the mastoid, squama, middle ear, internal auditory canal, glenoid fossa, eustachian tube, petrous apex, or styloid process. ${ }^{1}$ 
Temporal bone osteomas usually occur in young patients as a single unilateral lesion. Its etiology is still unknown but it is believed that they originate from the bone capsule's connective tissue ${ }^{2}$ with genetic and inflammatory theories suggested. ${ }^{3}$

In 2014 Yoon et al., ${ }^{3}$ reported two cases of middle ear osteomas and reviewed 32 papers reporting 34 other cases starting from the very first recorded case by Thomas in $1964 .{ }^{4}$ We reviewed MEDLINE database and only three other cases reported since then., ${ }^{2,5,6}$ Including the patient in this study there were 25 males and 15 females with a male predominance 1.67:1. The age of patients ranging from 5 year old to 57 years old with mean age of 29.3 .

As regards hearing, most osteomas in the middle ear present with conductive hearing loss. The mechanism is thought to be due to ossicular chain fixation, pathology of the tympanic membrane due to growth of the tumor towards the ear canal or obliteration of the round window. However they may be asymptomatic and discovered incidentally especially if there is no affection or connection to the ossicular chain. ${ }^{3}$ In our review 29 cases $(72.5 \%)$ had conductive hearing loss; three cases $(7.5 \%)$ had mixed hearing loss and six cases $(15 \%)$ asymptomatic.

It has been reported that middle ear osteomas may present with other manifestations such as vestibular manifestations, facial palsy, mixed hearing loss, Tullio phenomenon, otorrhea, discharge and tinnitus. ${ }^{3,6-8}$

CT scan is the recommended complementary image as it defines the extent and probable origin of the lesion also detecting any secondary manifestations of the tumor. ${ }^{2}$ The promontory is the most commonly involved site, followed by incus, pyramidal process, and the anterolateral wall of the epitympanum. ${ }^{3}$

Middle ear osteoma should be considered in the differential diagnosis of any bony growth originating in the middle ear, such as fenestral otospongiosis, ossifying hemangiomas, osteoid osteomas, benign osteoblastoma, ossifying fibroma, fibrous dysplasia, osteochondroma, chondroma, calcified meningioma, isolated eosinophilic granuloma, giant cell tumor and malignant lesions such as osteosarcoma and osteoblastic metastasis. ${ }^{9}$

In our review, 36 cases were managed surgically while 4 cases were managed conservatively. Generally, middle ear osteomas tend to be small and tend to remain stationary in size, therefore for small, asymptomatic middle ear osteomas conservative and periodic evaluation is the management option of choice. However in patients with significant conductive hearing loss or when there are other complications associated, surgical removal is preferred., ${ }^{3,6}$

\section{Conclusion}

Middle ear osteoma is a rare tumor, but should be considered in the differential diagnosis of middle ear masses. Patients may be asymptomatic or present commonly with conductive hearing loss. CT scan is the diagnostic imaging modality and should be considered in the assessment of children presenting with conductive hearing loss. Small asymptomatic lesions are managed conservatively with routine follow up while surgery is reserved for symptomatic cases.

\section{Acknowledgments}

None.

\section{Conflict of interest}

The author declares there is no conflict of interest.

\section{References}

1. Denia A, Perez F, Canalis RR, et al. Extracanalicular osteomas of the temporal bone. Arch Otolaryngol. 1979;105(12):706-709.

2. Toro PC, Castillo AC, Martínez RM, et al. Middle Ear Promontory Osteoma. Am J Otolaryngol. 2014;35(5):626-627.

3. Yoon YS, Yoon YJ, Lee EJ, et al. Incidentally detected middle ear osteoma: Two cases reports and literature review. Am J Otolaryngol. 2014;35(4):524-528.

4. Thomas R. Familial Osteoma of the Middle Ear. J Laryngol Otol. 1964;78:805-807.

5. Abouzayd M, Seghir A. Epitympanic osteoma of the middle ear: A case report and literature review. Rev Laryngol Otol Rhinol (Bord). 2015;136(2):81-83.

6. Curtis K, Bance M, Carter M, et al. Middle ear osteoma causing progressive facial nerve weakness: a case report. $J$ Med Case Rep. $2014 ; 8(1): 310$

7. Kim CW1, Oh SJ, Kang JM, et al. Multiple osteomas in the middle ear. Eur Arch Otorhinolaryngol. 2006;263(12):1151-1154.

8. Hornigold R, Pearch BJ, Gleeson MJ. An osteoma of the middle ear presenting with the Tullio phenomenon. Skull Base. 2003;13(2):113-117.

9. Ben-Yaakov A, Wohlgelernter J, Gross M. Osteoma of the lateral semicircular canal. Acta Otolaryngol. 2006;126(9):1005-1007. 